\title{
Maternal factors affecting outcome of induction of labour
}

\author{
Shravani Devarasetty*, S. Habeebullah
}

Department of Obstetrics and Gynecology, Mahatma Gandhi Medical College and Research Institute, Puducherry, India

Received: 28 March 2019

Revised: 11 October 2019

Accepted: 25 October 2019

\section{*Correspondence:}

Dr. Shravani Devarasetty,

E-mail: dshravani51190@gmail.com

Copyright: (c) the author(s), publisher and licensee Medip Academy. This is an open-access article distributed under the terms of the Creative Commons Attribution Non-Commercial License, which permits unrestricted non-commercial use, distribution, and reproduction in any medium, provided the original work is properly cited.

\section{ABSTRACT}

Background: Induction of labour is a common procedure in modern obstetrics and accounts for $20 \%$ among all deliveries. This study aims to assess the factors associated with success/failure of induction of labour.

Methods: This is a cohort study involving 220 women who underwent induction of labour in the department of obstetrics and gynaecology, MGMCRI from December 2016 to May 2018. After obtaining informed consent, patients were recruited into the study. Maternal parameters like age, parity, gestational age, BMI, Bishop score, indication of induction, method of induction, mode of delivery, maternal complications and neonatal parameters like Apgar score, birth weight and NICU admission were analyzed. Association of all parameters with mode of delivery was done by chi square test or Fisher exact test.

Results: Out of 220 women who were induced, vaginal delivery rate was $56.4 \%$. Vaginal delivery rate was high in young women of age 20-25 years $(65.2 \%)$, multiparous women $(65.1 \%)$, gestational age of $>40-42$ weeks $(64.7 \%)$, with normal BMI $(67.7 \%)$, with Bishop score $\geq 5(94.6 \%)$, induced for PROM and postdates $(68.6 \%)$ and induced with single agent (74\%). Most common indication of caesarean section was fetal distress (43.7\%) followed by meconium stained liquor $(30.2 \%)$. There were no adverse perinatal outcomes.

Conclusions: Women of age 20-25 years, normal BMI and induced with single agent showed statistically significant successful induction of labour.

Keywords: Bishop score, Caesarean section, Induction of labour, Vaginal delivery

\section{INTRODUCTION}

Induction is a common procedure in modern obstetrics and accounts for $20 \%$ among all deliveries. ${ }^{1}$ In the United States, the rate of labour induction increased gradually from $9.5 \%$ to $19.4 \% .^{2}$

Reasons for these differences relate to the widespread availability of cervical ripening agents, pressure from patients, convenience for physicians, logistic factors, psychosocial reasons, and fear of litigation. ${ }^{3}$ The goal of induction of labour is to pre-empt the natural process of labour by initiating its onset artificially by stimulating cervical ripening and uterine contractions before this occurs spontaneously. Induction of labour has merit as a therapeutic option when benefits of expeditious delivery outweigh the risk of continuing the pregnancy. The indications of induction have increased over the years leading to increase in rate of induction of labour. The indication of induction with unfavourable cervix can be medical or elective. Medical induction is when there is some maternal or fetal indication whereas elective induction is for the convenience of the individual without any medical indication. ${ }^{4}$

The favourability of the cervix has a substantial impact on the potential success of any labour induction. Factors that contribute towards increasing the risks of a caesarean 
section following labour induction include unfavourable cervix, nulliparity, obesity, mother's age above 30 years, fetal macrosomia, use of epidural analgesia, use of magnesium sulphate and chorioamnionitis. ${ }^{5}$

Most common methods for labour induction especially with an unfavourable cervix include intra vaginal insertion of Dinoprostone (PGE2), prostaglandin E1 (PGE1) analogue Misoprostol or intra-cervical insertion of Foley catheter. Regardless of cervical status and parity, vaginal delivery can be anticipated in the majority of patients undergoing labour induction. To avoid potential risks associated with the procedure, the woman and her fetus need to be monitored closely. This can strain the limited health-care resources in under-resourced settings.

This study was undertaken to identify the factors that affect the success and failure of induction of labour and thus to help improve quality of induction of labour and decrease unnecessary indications of the procedure.

\section{METHODS}

This was a prospective cohort study, which was conducted in the department of obstetrics and gynaecology, Mahatma Gandhi Medical College and Research Institute Hospital, a tertiary care hospital. The Institutional Human Ethics Committee approved this study. The study involved antenatal mothers and neonates. Study period was from December 2016 to May 2018. The pregnant women who were fulfilling the inclusion and exclusion criteria and willing to participate in the study were recruited. Written and informed consent was obtained from all patients who participated in the study. All related data were collected and entered into the proforma sheet. The study included women with singleton pregnancy with gestational age of 37-42 weeks with vertex presentation and adequate pelvis and excluded women with fetal anomalies, rupture of membranes for $>12$ hours, chorioamnionitis, uterine scar and antepartum haemorrhage.

\section{Statistical analysis}

Continuous variables like age and BMI were expressed as mean and standard deviation. Individual parameters like age, parity, gestational age, BMI, Bishop score, indication of induction and method of induction were shown as percentages. Association of all parameters with mode of delivery was analysed using Chi-square test.

\section{RESULTS}

During the study period there were a total of 2,643 deliveries. Of them 773 women were induced giving the rate of induction of labour as $29.2 \%$. On analysing the success of induction, the vaginal delivery rate was $56.4 \%$ and caesarean section rate was $43.6 \%$ and further analysis of various parameters with mode of delivery was as follows:
Table 1: Age and mode of delivery.

\begin{tabular}{|c|c|c|c|}
\hline \multirow[b]{2}{*}{$\begin{array}{l}\text { Age } \\
\text { (years) }\end{array}$} & \multicolumn{2}{|c|}{ Mode of delivery } & \multirow[b]{2}{*}{$\begin{array}{l}\text { p } \\
\text { value\# }\end{array}$} \\
\hline & $\begin{array}{l}\text { Vaginal } \\
\text { delivery } \mathbf{N}(\%)\end{array}$ & $\begin{array}{l}\text { Caesarean } \\
\text { section } \mathbf{N}(\%)\end{array}$ & \\
\hline $20-25$ & $86(65.2)$ & $46(34.8)$ & \multirow{3}{*}{$0.001 *$} \\
\hline $26-30$ & $35(50.7)$ & $34(49.3)$ & \\
\hline $31-35$ & $3(15.8)$ & $16(84.2)$ & \\
\hline
\end{tabular}

Note: \# p value based on Chi-square test, * statistically significant $(\mathrm{p}<0.05)$.

Vaginal delivery rate was $65.2 \%$ in $20-25$ years age group versus $15.8 \%$ in $31-35$ years age group (Table 1 ).

Table 2: Parity and mode of delivery.

\begin{tabular}{|c|c|c|c|}
\hline \multirow[b]{2}{*}{ Parity } & \multicolumn{2}{|c|}{ Mode of delivery } & \multirow[b]{2}{*}{$\begin{array}{l}\text { p } \\
\text { value\# }\end{array}$} \\
\hline & $\begin{array}{l}\text { Vaginal } \\
\text { delivery } \mathbf{N}(\%)\end{array}$ & $\begin{array}{l}\text { Caesarean } \\
\text { section N (\%) }\end{array}$ & \\
\hline Primi & $70(51.1)$ & $67(48.9)$ & \multirow{2}{*}{$0.04 *$} \\
\hline Multi & $54(65.1)$ & $29(34.9)$ & \\
\hline
\end{tabular}

Note: \# p value based on Chi-square test, $*$ statistically significant $(\mathrm{p}<0.05)$.

Vaginal delivery rate was $65.1 \%$ in multiparous women versus $51.1 \%$ in primigravidae (Table 2).

Table 3: Gestational age and mode of delivery.

\begin{tabular}{|llll|}
\hline \multirow{2}{*}{$\begin{array}{l}\text { Gestational } \\
\text { age }\end{array}$} & $\begin{array}{l}\text { Mode of delivery } \\
\text { Vaginal } \\
\text { delivery } \\
\mathbf{N}(\boldsymbol{\%})\end{array}$ & $\begin{array}{l}\text { Caesarean } \\
\text { section } \\
\mathbf{N}(\%)\end{array}$ & p \\
value\# \\
\hline $37-40$ weeks & $91(53.8)$ & $78(46.2)$ & \multirow{2}{*}{0.17} \\
\hline$>40-42$ weeks & $33(64.7)$ & $18(35.3)$ & \\
\hline
\end{tabular}

Note: \# p value based on Chi-square test.

Vaginal delivery rate was $53.8 \%$ in $37-40$ weeks versus $64.7 \%$ in $>40-42$ weeks (Table 3 ).

Table 4: BMI and mode of delivery.

\begin{tabular}{|c|c|c|c|}
\hline \multirow[b]{2}{*}{ BMI } & \multicolumn{2}{|c|}{ Mode of delivery } & \multirow[b]{2}{*}{$\begin{array}{l}\text { p } \\
\text { value\# }\end{array}$} \\
\hline & $\begin{array}{l}\text { Vaginal } \\
\text { delivery } \\
\mathbf{N}(\%)\end{array}$ & $\begin{array}{l}\text { Caesarean } \\
\text { section } \\
\text { N }(\%)\end{array}$ & \\
\hline Normal & $67(67.7)$ & $32(32.3)$ & \multirow{3}{*}{$0.001 *$} \\
\hline Overweight & $45(60.8)$ & $29(39.2)$ & \\
\hline Obese & $12(25.5)$ & $35(74.5)$ & \\
\hline
\end{tabular}

Note: \# p value based on Chi-square test, * statistically significant $(\mathrm{p}<0.05)$.

Vaginal delivery rate was $67.7 \%$ in normal BMI women versus $25.5 \%$ in obese women (Table 4 ).

Vaginal delivery rate was high in PROM and postdates women (68.6\%) (Table 5). Bishop score $<5$ was associated with significantly high caesarean section rate 
and score $\geq 5$ was associated with high vaginal delivery in $94.6 \%$ (Table 6).

Table 5: Indication of induction and mode of delivery.

\begin{tabular}{|c|c|c|c|}
\hline \multirow[b]{2}{*}{$\begin{array}{l}\text { Indication of } \\
\text { induction }\end{array}$} & \multicolumn{2}{|c|}{ Mode of delivery } & \multirow[b]{2}{*}{$\begin{array}{l}\text { p } \\
\text { value\# }\end{array}$} \\
\hline & $\begin{array}{l}\text { Vaginal } \\
\text { delivery } \\
\mathbf{N}(\%)\end{array}$ & $\begin{array}{l}\text { Caesarean } \\
\text { section } \\
\mathbf{N}(\%)\end{array}$ & \\
\hline Oligohydramnios & $46(58.2)$ & $33(41.8)$ & \multirow{8}{*}{$0.008^{*}$} \\
\hline PROM & $35(68.6)$ & $16(31.4)$ & \\
\hline Post dates & $24(68.6)$ & $11(31.4)$ & \\
\hline GHTN & $8(38.1)$ & $13(61.9)$ & \\
\hline GDM on insulin & $5(25)$ & $15(75)$ & \\
\hline GDM & $4(57.1)$ & $3(42.9)$ & \\
\hline $\begin{array}{l}\text { Prolonged latent } \\
\text { phase }\end{array}$ & $1(20)$ & $4(80)$ & \\
\hline $\begin{array}{l}\text { Non-reactive } \\
\text { NST }\end{array}$ & $1(50)$ & $1(50)$ & \\
\hline
\end{tabular}

Note: \# p value based on Chi-square test, * statistically significant $(\mathrm{p}<0.05)$.

Table 6: Bishop score and mode of delivery.

\begin{tabular}{|llll|}
\multirow{2}{*}{ Mode of delivery } & \multicolumn{2}{l}{ Bishop score } & p \\
& $\mathbf{5}$ & $\mathbf{2}$ & value\# \\
& $\mathbf{N}(\boldsymbol{\%})$ & $\mathbf{N}(\boldsymbol{\%})$ & \\
\hline Vaginal delivery & $89(48.6)$ & $35(94.6)$ & \multirow{2}{*}{$<0.001 *$} \\
\hline Caesarean section & $94(51.4)$ & $2(5.4)$ & \\
\hline
\end{tabular}

Note: \# p value based on Chi-square test, $*$ statistically significant $(\mathrm{p}=<0.05)$.

Table 7: Method of induction and mode of delivery.

\begin{tabular}{|c|c|c|c|}
\hline \multirow[b]{2}{*}{ Mode of delivery } & \multicolumn{2}{|c|}{ Method of induction } & \multirow[b]{2}{*}{$\begin{array}{l}\text { p } \\
\text { value\# }\end{array}$} \\
\hline & $\begin{array}{l}\text { Single } \\
\text { agent } \\
\text { N }(\%)\end{array}$ & $\begin{array}{l}\text { Multiple } \\
\text { agents } \\
\text { N }(\%)\end{array}$ & \\
\hline Vaginal delivery & $71(74)$ & $53(42.7)$ & \multirow{2}{*}{$<0.001 *$} \\
\hline Caesarean section & $25(26)$ & $71(57.3)$ & \\
\hline
\end{tabular}

Vaginal delivery rate was $74 \%$ in single agent group versus $42.7 \%$ in multiple agent group and is statistically significant (Table 7).

Table 8: Indication for caesarean section.

\begin{tabular}{|lll|}
\hline Indication for caesarean section & $\mathbf{N}(96)$ & $\%$ \\
\hline Fetal distress & 42 & 43.7 \\
\hline Cephalo pelvic disproportion & 12 & 12.5 \\
\hline Meconium stained liquor & 29 & 30.2 \\
\hline Failed Induction & 13 & 13.5 \\
\hline
\end{tabular}

Majority of caesarean sections was due to fetal distress $(43.7 \%)$ and followed by thick meconium stained liquor $(30.2 \%)$ (Table 8$)$.
Table 9: Maternal complications.

\begin{tabular}{|lll|}
\hline Maternal complication & N $(220)$ & $\%$ \\
\hline Nil & 212 & 96.4 \\
\hline Postpartum haemorrhage & 6 & 2.7 \\
\hline $3^{\text {rd }}$ degree perineal tear & 2 & 0.9 \\
\hline
\end{tabular}

Majority of women had no complications. Post-partum haemorrhage was seen in $2.7 \%$ cases and $3^{\text {rd }}$ degree perineal tear in $0.9 \%$ cases (Table 9 ).

Table 10: Mode of delivery and 5 min APGAR score.

\begin{tabular}{|c|c|c|c|}
\hline \multirow[b]{2}{*}{$\begin{array}{l}\text { APGAR } \\
\text { score } \\
\text { At } 5 \text { min }\end{array}$} & \multicolumn{2}{|c|}{ Mode of delivery } & \multirow[b]{2}{*}{$\begin{array}{l}\mathbf{p} \\
\text { value\# }\end{array}$} \\
\hline & $\begin{array}{l}\text { Vaginal } \\
\text { delivery } \\
\mathbf{N}(\%)\end{array}$ & $\begin{array}{l}\text { Caesarean } \\
\text { section } \\
\mathbf{N}(\%)\end{array}$ & \\
\hline$\geq 7$ & $123(99.2)$ & $91(94.8)$ & \multirow{2}{*}{0.06} \\
\hline$<7$ & $1(0.8)$ & $5(5.2)$ & \\
\hline
\end{tabular}

Note: \# p value based on Chi-square test.

Apgar score at 5 min in new born was $\geq 7$ in $99.2 \%$ vaginal delivery and $94.8 \%$ caesarean section group (Table 10).

Table 11: Mode of delivery and birth weight.

\begin{tabular}{|c|c|c|c|}
\hline \multirow[b]{2}{*}{ Birth weight } & \multicolumn{2}{|c|}{ Mode of delivery } & \multirow[b]{2}{*}{$\begin{array}{l}\mathbf{p} \\
\text { value\# }\end{array}$} \\
\hline & $\begin{array}{l}\text { Vaginal } \\
\text { delivery } \\
\mathbf{N}(\%)\end{array}$ & $\begin{array}{l}\text { Caesarean } \\
\text { section } \\
\mathbf{N}(\%)\end{array}$ & \\
\hline$<2.5 \mathrm{~kg}$ & $18(75)$ & $6(25)$ & \multirow{4}{*}{$0.001 *$} \\
\hline$\geq 2.5 \mathrm{~kg}$ to $3 \mathrm{~kg}$ & $73(65.2)$ & $39(34.8)$ & \\
\hline$>3$ to $3.5 \mathrm{~kg}$ & $24(37.5)$ & $40(62.5)$ & \\
\hline$>3.5 \mathrm{~kg}$ & $9(45)$ & $11(55)$ & \\
\hline
\end{tabular}

Note: \# p value based on Chi-square test, * statistically significant $(\mathrm{p}<0.05)$.

Vaginal delivery rate was $75 \%$ in birth weight $<2.5 \mathrm{~kg}$ versus $45 \%$ in birth weight $>3.5 \mathrm{~kg}$ and it was statistically significant (Table 11).

Table 12: NICU admission.

\begin{tabular}{|lll|}
\hline NICU admission & N $(220)$ & $\%$ \\
\hline No & 212 & 96.4 \\
\hline Yes & 8 & 3.6 \\
\hline
\end{tabular}

NICU admission for $>24$ hours was required for only $3.6 \%$ new-borns (Table 12).

\section{DISCUSSION}

Rate of induction in our institution was $29.2 \%$ during the study period. Similarly, high rates of induction were observed in developed countries is between $20-30 \% .^{6-8}$ The WHO quoted a figure of $12 \%$ for Asia. ${ }^{9}$ Ours being a tertiary care hospital, a number of high-risk pregnancies are referred which may need induction of labour. 
The definition we followed for successful induction was achieving vaginal delivery. In the present study $56.4 \%$ delivered vaginally. A study from Pakistan showed $18 \%$ failure rate of induction. ${ }^{10}$

Women who underwent induction of labour were in the age group of 20-25 years in the study. Mean age of these women was 25.1 years. The vaginal delivery rate in this age group was $65.2 \%$ compared to $15.8 \%$ in women above 30 years of age. A previous study showed that the mean age of induction was 22.3 years and vaginal delivery rate was $51.32 \% .{ }^{11}$ However, there are not many studies which analysed age and induction of labour.

Primigravidae constituted $62.3 \%$ and $37.7 \%$ were multiparous in the study. The vaginal delivery rate in nulliparous women was $51.1 \%$ versus $65.1 \%$ in multiparous women. Khan et al, from Pakistan did a study in which $61 \%$ of women were nulliparous and vaginal delivery rate was $74.7 \%$ in nulliparous women versus $93.2 \%$ in multiparous women. Failed induction was 4.6 times more likely in nulliparous women. ${ }^{10}$

In the study $76.8 \%$ of women were in gestational age of $37-40$ weeks and $23.2 \%$ were in $>40-42$ weeks. Generally, induction of labour in older gestational age is associated with increased risk of caesarean section. But in our study the vaginal delivery rate in early gestational age (37 to 40 weeks) was $53.8 \%$ versus $64.7 \%$ in late gestational age (> 40-42 weeks). This observation was supported by ACOG guideline which says that elective induction before 39 weeks of gestation usually results in higher Caesarean section rates12 though Khan et al had contrary results which was probably due to elective induction at 40 weeks. ${ }^{10}$

Body mass index of the women who underwent induction of labour was recorded. Majority of the women were in normal BMI group (45\%) and women in obese group were $21.4 \%$. Mean BMI of women in the study was 25.6 $\mathrm{kg} / \mathrm{m}^{2}$. The outcome of induction of labour is also associated with body mass index of the women. Caesarean section rate was $32.3 \%$ in women with normal BMI versus $74.5 \%$ in obese women. A study in 2015 showed mean BMI as $26.5 \mathrm{~kg} / \mathrm{m}^{2}$ and it was concluded that caesarean section rates were higher in women with higher BMI. ${ }^{13}$

There are many indications for induction of labour. The most common indications being oligohydramnios, pre labour rupture of membranes and post-dated pregnancy which account to $75 \%$ of cases, followed by gestational hypertension $(9.5 \%)$ and gestational diabetes $(9.1 \%)$. Vaginal delivery rates were higher in oligohydramnios (58.2\%), PROM (68.6\%) and post-dated (68.6\%) women. But Caesarean section rates were higher in gestational hypertension $(61.9 \%)$ and GDM $(75 \%)$ women. A systematic review done in 2009 showed post-dated pregnancy, PROM and oligohydramnios as most common indications for induction which supports the present study. ${ }^{14}$ Induction of labour in post-dated pregnancy associated with successful outcome of induction was supported by another study. ${ }^{15}$

In the present study, favorability of cervix was assessed based on pre-induction Bishop score. They were divided into Bishop score $<5(83.2 \%)$ and Bishop score $\geq 5$ $(16.8 \%)$. Majority of women were with Bishop score $<5$. Favorability of cervix is the main predictor for successful induction of labour. Vaginal delivery rate in Bishop score $<5$ was $48.6 \%$ versus $94.6 \%$ in Bishop score $\geq 5$. In another study failure rate was $84 \%$ in women with Bishop score $<5$ versus $18 \%$ with Bishop score $\geq 5$. $^{10}$

Methods of induction of labour were divided into single agent group and multiple agent group. In single agent group usually either oral misoprostol or vaginal PGE2 gel was used whereas in multiple agent group mostly Foley catheter followed by PGE2 gel were used for cervical ripening. Women in single agent group were $43.6 \%$ and women in multiple agent group were $56.4 \%$. In our study vaginal delivery rate in single agent group was $74 \%$ versus $42.7 \%$ in multiple agent group. Similar results were obtained in a study which showed $76.7 \%$ vaginal delivery in misoprostol group versus $56.8 \%$ in Foley catheter group. ${ }^{16}$ And another study showed $70 \%$ vaginal delivery in PGE2 group versus $56 \%$ in Foley catheter group. ${ }^{17}$ We have not analysed specifically any method of induction.

Mode of delivery in the study was vaginal in $56.4 \%$ and caesarean section in $43.6 \%$. This was not statistically significant. There are many factors that led to this outcome like maternal age, parity, gestational age at which the women were induced, BMI, Bishop score, indication of induction and method of induction which were explained earlier. A recent study in 2016 showed that $63.5 \%$ had vaginal delivery and $36.5 \%$ had caesarean section following induction of labour. ${ }^{18}$

The most common indication for caesarean section in the study was fetal distress $(43.7 \%)$ followed by thick meconium stained liquor $(30.2 \%)$. Another recent study also showed fetal distress in $22.69 \%$ and meconium stained liquor in $19.33 \%$ as indications for caesarean section. ${ }^{19}$

There were no significant maternal complications. Postpartum haemorrhage was seen in $2.7 \%$ cases and $3^{\text {rd }}$ degree perineal tear was in $0.9 \%$ of women. Very few studies have recorded maternal complications. Cervical tear and PPH were observed $4 \%$ each in a study from Bangladesh. $^{20}$

Apgar score at 5 minutes was $\geq 7$ in most of the babies. Only $2.7 \%$ babies had Apgar score $<7$ at 5 minutes. $89.1 \%$ new borns had birth weight $\geq 2.5 \mathrm{~kg}$. Vaginal delivery rate was $75 \%$ in birth weight $<2.5 \mathrm{~kg}$ versus $45 \%$ in birth weight $>3.5 \mathrm{~kg}$. Higher birth weight babies are usually associated with increased risk of failed 
induction. ${ }^{21}$ Other studies concluded that induction of labour was associated with increased caesarean section risk and adverse perinatal outcomes. ${ }^{22,23}$ Birth asphyxia was seen in $16 \%$ following induced delivery whereas in our study only 8 babies $(3.6 \%)$ were admitted in NICU for more than 24 hours. ${ }^{20}$

The limitations of the study are no single protocol of inducing agents was used and cervical assessment was done by different personnel; so, the chances of bias persist.

\section{CONCLUSION}

We conclude that success of induction of labour that is achieving vaginal delivery was $56.4 \%$ in the study. Age < 30 years, lower BMI and single inducing agent were significantly associated with successful induction of labour. Nulliparity, indication for induction, gestational age $\leq 40$ weeks, pre-induction Bishop score $<5$ and increased birth weight $(>3 \mathrm{~kg}$ ) were associated with increased caesarean section rate. There were no significant maternal or perinatal complications associated with induction of labour.

Funding: No funding sources

Conflict of interest: None declared

Ethical approval: The study was approved by the Institutional Ethics Committee

\section{REFERENCES}

1. Inducing labour, Guidance and guidelines, NICE. 2008: Available at: URI:https://www.nice.org.uk /guidance/qs60.

2. Zhang J, Yancey MK, Henderson CE. U.S. national trends in labor induction, 1989-1998. J Reprod Med. 2002;47(2):120-4.

3. Rayburn WF, Zhang J. Rising rates of labor induction: present concerns and future strategies. Obstet Gynecol. 2002;100(1):164-7.

4. Järvelin MR, Hartikainen-Sorri AL, Rantakallio P. Labour induction policy in hospitals of different levels of specialisation. $\mathrm{Br} \mathrm{J}$ Obstet Gynaecol. 1993;100(4):310-5.

5. Vrouenraets FPJM, Roumen FJME, Dehing CJG, van den Akker ESA, Aarts MJB, Scheve EJT. Bishop score and risk of cesarean delivery after induction of labor in nulliparous women. Obstet Gynecol. 2005;105(4):690-7.

6. Zeitlin J, Mohangoo AD, Delnord M, Cuttini M, EURO-PERISTAT scientific committee. The second European perinatal health report: documenting changes over 6 years in the health of mothers and babies in Europe. J Epidemiol Comm Health. 2013;67(12):983-5.

7. WHO Recommendations for Induction of Labour. Geneva: World Health Organization; 2011.

8. Martin JA, Hamilton BE, Ventura SJ, Osterman MJK, Mathews TJ. Births: final data for 2011. Natl
Vital Stat Rep Cent Dis Control Prev Natl Cent Health Stat Natl Vital Stat Syst. 2013;62(1):1-69.

9. Vogel JP, Souza JP, Gülmezoglu AM. Patterns and outcomes of induction of labour in Africa and Asia: a secondary analysis of the WHO global survey on maternal and neonatal health. PlosOne. 2013;8(6):e65612.

10. Khan NB, Ahmed I, Malik A, Sheikh L. Factors associated with failed induction of labour in a secondary care hospital. JPMA J Pak Med Assoc. 2012;62(1):6-10.

11. Marroquin GA, Tudorica N, Salafia CM, Hecht R, Mikhail M. Induction of labor at 41 weeks of pregnancy among primiparas with an unfavorable Bishop score. Arch Gynecol Obstet. 2013;288(5):989-93.

12. ACOG Committee on Practice Bulletins - Obstetrics. ACOG Practice Bulletin No. 107: Induction of labor. Obstet Gynecol. 2009;114(2 Pt 1):386-97.

13. Lee HR, Kim MN, You JY, Choi SJ, Oh SY, Roh $\mathrm{CR}$, et al. Risk of cesarean section after induced versus spontaneous labor at term gestation. Obstet Gynecol Sci. 2015;58(5):346-52.

14. Mozurkewich E, Chilimigras J, Koepke E, Keeton K, King VJ. Indications for induction of labour: A bestevidence review. MCN Am J Matern Nurs. 2009;34:6.

15. Mishanina E, Rogozinska E, Thatthi T, Uddin-Khan $\mathrm{R}$, Khan KS, Meads C. Use of labour induction and risk of cesarean delivery: a systematic review and meta-analysis. CMAJ Can Med Assoc J Assoc Medicale Can. 2014;186(9):665-73.

16. Noor N, Ansari M, Ali SM, Parveen S. Foley Catheter versus vaginal misoprostol for labour induction. Int J Repro Med. 2015. Available at: https://www.hindawi.com/journals/ijrmed/2015/8457 $35 /$.

17. Dahlia Mary A. Induction of Labour - Foley's Catheter versus Prostaglandin E2 Gel. Madras Medical College, Chennai; 2010. Available at: http://repository-tnmgrmu.ac.in/4094/.

18. Bello. Predictors of successful induction of labour at a tertiary obstetric service in Southwest Nigeria. Available at: http://www.tjogonline.com/article.asp ?issn=0189-5117; year $=2016$; volume $=33$;issue $=$ $2 ;$ spage $=143$; epage $=148 ;$ aulast $=$ Bello.

19. Zandvakili F, Shahoei R, Roshani D, Nasab LH. Labor induction and the risk of cesarean delivery among term pregnancies. Int J Med Res Health Sci. 2018;5(10):128-33.

20. Sultana R, Begum K, Sultana N, Sultana N, Munmun $\mathrm{SA}$, Ara R, et al. Induction of labour in prolonged pregnancy and its outcome. Med Today. 2015;26(2):100-3.

21. Vahratian A, Zhang J, Troendle JF, Savitz DA, Siega-Riz AM. Maternal prepregnancy overweight and obesity and the pattern of labor progression in term nulliparous women. Obstet Gynecol. 2004;104(5 Pt 1):943-51. 
22. Boulvain M, Kelly A, Irion O. Intracervical prostaglandins for induction of labour. Cochrane Database Syst Rev. 2008;(1):CD006971.

23. Davey MA, King J. Caesarean section following induction of labour in uncomplicated first births: a population-based cross-sectional analysis of 42,950 births. BMC Preg Childbirth. 2016;16:92.

Cite this article as: Devarasetty $\mathrm{S}$, Habeebullah $\mathrm{S}$. Maternal factors affecting outcome of induction of labour. Int J Reprod Contracept Obstet Gynecol 2019;8:4705-10. 